\title{
TORSION OF OVARY IN MRKH SYNDROME PRESENTING AS IRREDUCIBLE SLIDING INGUINAL HERNIA
}

Sneha Palepu', Uday Kumar², Md. Jawed Akhter ${ }^{3}$, Yaramati Avinash ${ }^{4}$

\section{HOW TO CITE THIS ARTICLE:}

Sneha Palepu, Uday Kumar, Md. Jawed Akhter, Yaramati Avinash. "Torsion of Ovary in MRKH Syndrome Presenting as Irreducible Sliding Inguinal Hernia". Journal of Evolution of Medical and Dental Sciences 2015; Vol. 4, Issue 73, September 10; Page: 12796-12799, DOI: 10.14260/jemds/2015/1843

\begin{abstract}
Inguinal hernias may have very unusual sac content. The Fallopian tube and ovary are found in $15 \%$ to $20 \%$ of the sliding hernias in females. Mayer-Rokitansky-Kuster-Hauser (MRKH) syndrome, is one of the associated genital anomalies with an incidence of 1:4500 female births. We report a rare case of sliding inguinal herniation of ovary with torsion \& fallopian tube in a 20 year old woman with MRKH syndrome type I. Preservation of ovarian function by repositioning the gonad followed by herniorrhaphy was done.
\end{abstract}

KEYWORDS: MRKH Syndrome, Sliding inguinal hernia, Torsion of ovary.

INTRODUCTION: Inguinal hernias may have very unusual sac content.(1,2) Sliding inguinal hernias of the uterus, fallopian tube, and ovary are rare in adult women.(3) Most cases have associated congenital anomalies of the genital tract.(4) Ovarian torsion and infarction have been encountered in $2 \%$ to $33 \%$ of the patients presenting as non-reducible groin swellings. (5) We report a case of sliding inguinal herniation of ovary \& fallopian tube with torsion of the right ovarian cyst in a 20 year old woman with MRKH syndrome type I.

CASE REPORT: A 20 years old female with bilateral reducible groin swellings since childhood and primary amenorrhea presented with right groin pain for 2 days. On examination $7 \times 5 \mathrm{~cm}$ oval, moderately tender irreducible swelling in the right inguinal region and $3 \times 3 \mathrm{~cm}$ oval, non-tender reducible swelling in the left inguinal region were present. Patient was thin built with a female phenotype and normal stature. Her breast development \& pubic hair pattern corresponded to tanners stage III, with sparse axillary hair.

Her external genitalia were normal. Per vaginal examination revealed blind vagina. Ultrasonography of abdomen and pelvis revealed $6 \times 4 \mathrm{~cm}$ mixed echogenic lesion in the right inguinal canal without vascularity and $3 \times 2 \mathrm{~cm}$ oval mixed echogenic lesion in the left inguinal canal without uterus and both ovaries in the pelvis. Magnetic Resonance Imaging (MRI) revealed well defined heterogeneously hyperintense T1 \& contrast enhancing lesions in the bilateral inguinal canals with multiseptated T2 hyperintense lesion in the right inguinal canal [Figure 1]. Her karyotype was 46XX and her hormonal profile was normal.

Intra-operatively, a sliding hernia of right side revealed an atretic ovary with a $5 \times 3 \mathrm{~cm}$ congested cyst and a $12 \mathrm{~cm}$ long rudimentary fallopian tube [Figure 2]. On the left side, a reducible sliding hernia with normal ovary and a paraovarian mass of $3 \times 2 \mathrm{~cm}$ was identified. The right ovary and the tube were excised followed by bilateral herniorrhaphy. Biopsy of the specimen revealed normal ovarian tissue with fallopian tube showing congested vessels and oedematous stroma with a thin walled cyst [Figure 3]. 


\section{CASE REPORT}

DISCUSSION: Embryologically, female inguinal canal encompasses two main anatomic structuresgubernaculum ovarii and processus vaginalis. Gubernaculum ovarii is a ligamentous structure which attaches to uterine cornua midway along its course. Superior to this attachment, it is called ovarian ligament which prevents ovarian descent into the inguinal canal and inferior to the attachment, it is the round ligament of uterus. Processus vaginalis is a small anterior evagination of parietal peritoneum which is usually obliterated by $8^{\text {th }}$ month of development.(6) Incomplete obliteration may result in indirect inguinal hernia.

An ovary in a hernia sac might be assumed to be a descended gonad, mimicking descent of the testis rather than simply prolapsed which presents as sliding hernia.(7) The ligament that lies in the inguinal hernia sac in females believed to be the round ligament of uterus is actually the suspensory ligament of the ovary.(8) It is supposed to be the female gubernaculum with altered anatomy and localization because of the absence of androgen responsiveness.(7)

MRKH is characterized by congenital aplasia of the uterus, upper $2 / 3$ of the vagina \& normal ovaries in women with normal female phenotype and normal 46, XX karyotype. Type I with isolated genital anomalies is less frequent than Type II.(9) This was a case of a 20 year old adult married woman with MRKH syndrome type I with an irreducible sliding inguinal hernia containing ovary and fallopian tube with torsion of the ovary which is extremely rare.

Strubbe et al. identified 6 among 91 MRKH patients with inguinal ovarian hernia.(10) Bazi et al. identified 7 well documented cases of MRKH with inguinal ovarian hernia, their patient became eighth.(11) An inguinal ovary is not at risk of compression of its blood supply but of torsion and infarction. (5) Management therefore is aimed at preserving the ovarian function by repositioning the gonad followed by herniorrhaphy as soon as the condition is recognized.(11)

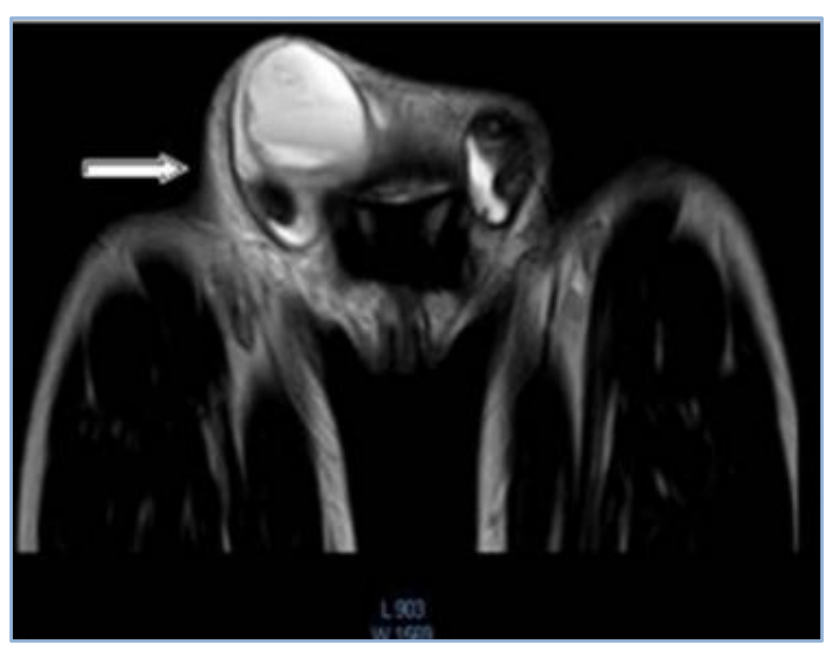

Fig. 1: (MRI of B/L Inguinal Region)

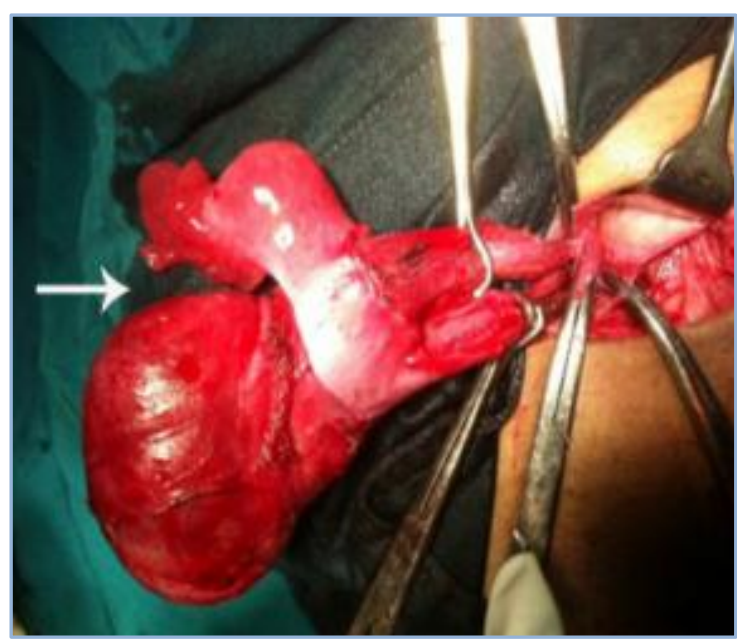

Fig. 2: (Ovary, Congested, Cyst \& Fallopian Tube) 


\section{CASE REPORT}

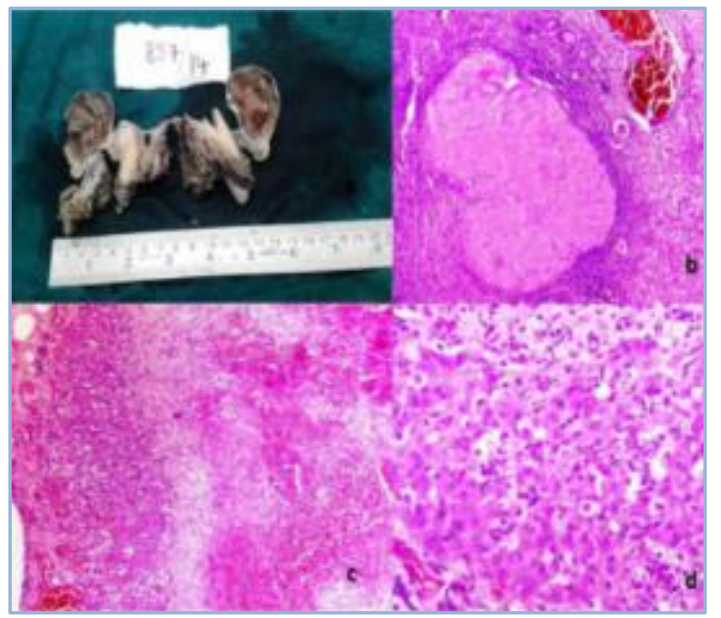

\section{Fig. 3: (HP of Ovary, Congested Cyst}

\& Fallopian Tube)

\section{REFERENCES:}

1. Goldstein R, Potts WJ. Inguinal hernia in female infants and children. Ann Surg 1958; 148:81922.

2. George EK, Oudesluys-Murphy AM, Madern GC, Cleyndert P, Blomjous JG. Inguinal hernias containing the uterus, fallopian tube, and ovary in premature female infants. J Pediatr 2000; 136:696-8.

3. Kokcu A, Malazgirt Z, Cetinkaya MB, Tosun M. Presence of a uterine horn and fallopian tube within an indirect hernial sac: report of a rare case. Hernia 2010; 14:325-7.

4. Wiley J, Chavez HA. Uterine adnexa in inguinal hernia in infant females: report of a case involving uterus, both uterine tubes and ovaries. West J Surg Obstet Gynecol 1957; 65:283-5.

5. Boley SJ, Cahn D, Laur T, Weinburg G, Kleinhaus S. The irreducible ovary: a true emergency. J Pediatr Surg 1991; 26:1035-8.

6. Moore KL, Persaud TVN. The Urogenital system. In. The Developing Human: Clinically Oriented Embryology. 7th ed. Philadelphia, PA: WB Saunders Co; 2003:324-5.

7. Ozbey H, Ratschek M, Schimpl G, Höllwarth ME. Ovary in hernia sac: prolapsed or a descended gonad? J Pediatr Surg 1999; 34:977-80.

8. Ando H, Kaneko K, Ito F, Seo T, Ito T. Anatomy of the round ligament in female infants and children with inguinal hernia. Br J Surg 1997; 84:404-9.

9. Karine Morcel, Laure Camborieux, Programme de Recherches sur les Aplasies Müllériennes (PRAM), Daniel Guerrier. Mayer-Rokitansky-Küster-Hauser (MRKH) syndrome. Orphanet Journal of Rare Diseases 2007; 2:13.

10. Strubbe EH, Willemsen WNP, Lemmens JAM, Thijn CJP, Roland R. Mayer-Rokitansky-KusterHauser syndrome: distinction between two forms based on excretory, urographic, sonographic, and laparoscopic findings. AJR Am J Roentgenol 1993; 160:331-4.

11. Bazi T, Berjawi G, Seoud M. Inguinal ovaries associated with Müllerian agenesis: case report and review. Fertil Steril. 2006; 85:5-8. 


\section{CASE REPORT}

\section{AUTHORS:}

1. Sneha Palepu

2. Uday Kumar

3. Md. Jawed Akhter

4. Yaramati Avinash

\section{PARTICULARS OF CONTRIBUTORS:}

1. Post Graduate, Department of General Surgery, Mamata Medical College, Khammam, Telengana.

2. Post Graduate, Department of General Surgery, Mamata Medical College, Khammam, Telengana.

3. Professor, Department of General Surgery, Mamata Medical College, Khammam, Telengana.

FINANCIAL OR OTHER COMPETING INTERESTS: None
4. Post Graduate, Department of General Surgery, Mamata Medical College, Khammam, Telengana.

\section{NAME ADDRESS EMAIL ID OF THE}

\section{CORRESPONDING AUTHOR:}

Md. Jawed Akhter,

Department of General Surgery, Mamata Medical College,

Khammam-507002, Telengana.

E-mail: dr_mdjawedakther@yahoo.com

Date of Submission: 27/08/2015.

Date of Peer Review: 28/08/2015.

Date of Acceptance: 05/09/2015.

Date of Publishing: 10/09/2015. 